\title{
Mutation of the p16/CDKN2 gene and loss of heterozygosity in malignant mucosal melanoma and adenoid cystic carcinoma of the head and neck
}

\author{
NORIHISA SUZUKI ${ }^{1}$, TAKESHI ONDA ${ }^{1,2}$, NOBUHARU YAMAMOTO ${ }^{1}$, \\ AKIRA KATAKURA $^{1}$, JUN-ETSU MIZOE ${ }^{2}$ and TAKAHIKO SHIBAHARA ${ }^{1}$ \\ ${ }^{1}$ Department of Oral and Maxillo-Facial Surgery, Tokyo Dental College, 1-2-2 Masago, Mihama-ku, \\ Chiba 261-8502; ${ }^{2}$ Department of Medical Physics, Research Center for Charged Particle Therapy, \\ National Institute of Radiological Sciences, 4-9-1 Anagawa, Inage-ku, Chiba 263-8555, Japan
}

Received April 2, 2007; Accepted May 25, 2007

\begin{abstract}
The purpose of this study was to investigate the molecular biological characteristics of malignant mucosal melanoma (MMM) and adenoid cystic carcinoma (ACC) of the head and neck. We analyzed the common genetic abnormalities that may help to identify the loci in the genes involved in the development of MMM and ACC of the head and neck by PCR-LOH on chromosomes 1p, 6q, 9p, 10q, $11 \mathrm{q}, 12 \mathrm{q}, 17 \mathrm{p}$, and 19q. $\mathrm{LOH}$ was observed in 6 of 12 cases of MMM and in 12 of 15 cases of ACC informative for at least one of the loci analyzed. One distinct deleted region was identified at chromosome $9 \mathrm{p} 21$. In addition, to identify a possible involvement of $p 16 / C D K N 2$ PCR-SSCP and autoDNA sequence analysis were also performed to detect any mutation of the $p 16 / C D K N 2$. Particularly, 2 missense mutations were detected in codon 225 and 226, both in MMM and ACC. There were mutational hot spots in the $p 16 / C D K N 2$ gene. These results suggested that mutation of the $p 16 / C D K N 2$ gene was a common factor in the development of human MMMs and ACCs, while this gene may be correlated with development and/or progression of a subtype and play a role in the oncogenesis of these cancers.
\end{abstract}

\section{Introduction}

Malignant mucosal melanoma (MMM) and adenoid cystic carcinoma (ACC) are two of the malignant tumors with the poorest prognosis. According to a previous report, the effective treatment for these diseases is carbon ion radiotherapy using heavy charged particles (1).

Correspondence to: Dr Takahiko Shibahara, Department of Oral and Maxillo-Facial Surgery, Tokyo Dental College, 1-2-2 Masago, Mihama-ku, Chiba 261-8502, Japan

E-mail: sibahara@tdc.ac.jp

Key words: p16/CDKN2, loss of heterozygosity, malignant mucosal melanoma, adenoid cystic carcinoma, head and neck cancer
Clinical trials of carbon ion radiotherapy for various cancers were initiated in June 1994 at the Hospital of the Research Center for Charged Particle Therapy, National Institute of Radiological Sciences (NIRS), using the world's first Heavy Ion Medical Accelerator in Chiba (HIMAC) dedicated to medical purposes (1). Preliminary results of phase II clinical trials have shown extremely favorable therapeutic results in the treatment of MMMs and ACCs that are otherwise intractable with conventional photon radiation $(2,3)$. As stated above, radiotherapy with heavy charged particles is significantly effective in the therapy of MMMs and ACCs of the head and neck. Radiotherapy using the HIMAC has some characteristics in common with conventional photon radiation. Firstly, HIMAC irradiation inflicts fatal damage upon the DNA of cancer cells so that cancer cell restoration is made difficult. Secondly, HIMAC irradiation affects cells at any stage of the cell cycle. Thirdly, the HIMAC irradiation has a cytocidal effect on cancer cells also in a hypoxic environment. Lastly, the distribution characteristics of HIMAC radiation are such as to minimize damage to normal tissues while limiting injury to the tumor only. However, no analysis method for the molecular biological assessment of the effectiveness of HIMAC radiation for MMMs and ACCs has yet been established. We therefore considered that the molecular biological characteristics such as loss of heterozygosity (LOH) and microsatellite instability (MSI) may become criteria for assessment of the effectiveness of HIMAC radiotherapy for MMM and ACC prior to therapy. In recent studies, LOH and MSI have been used for assessing allelic imbalances. For example, allelic imbalances including $\mathrm{LOH}$ and MSI in malignant cells have proven useful for mapping DNA regions potentially harboring candidate tumor suppressor genes (TSG). According to a previous study, a high incidence of $\mathrm{LOH}$ has been detected in head and neck squamous cell carcinomas (SCC) on several chromosome arms, including $2 \mathrm{q}, 3 \mathrm{p}, 4 \mathrm{q}, 5 \mathrm{q}, 7 \mathrm{q}, 8 \mathrm{p}, 9 \mathrm{p}, 10 \mathrm{q}, 11 \mathrm{q}, 13 \mathrm{q}, 18 \mathrm{q}, 20 \mathrm{q}, 21 \mathrm{q}$, and $22 q(4-7)$, where candidate TSGs may be present.

We thus made a literature search to look for evidence of prior gene analysis common to MMM and ACC, but the extant literature does not provide any information on gene 
seat ranking common to both diseases. There were few reports related to MMM, while most focused on cutaneos melanoma (8). However, there was a significant number of reports in the literature referring to gene analysis of ACC $(9,10)$. The limited number of loci tested and the varietal incidence of genetic alterations in these studies make it difficult to assess the regions of chromosomes $1 \mathrm{p}, 6 \mathrm{q}, 9 \mathrm{p}$, $10 \mathrm{q}, 11 \mathrm{q}, 12 \mathrm{q}, 17 \mathrm{p}$, and 19q (11-14) involved in cutaneos melanoma and ACC of the head and neck. We paid particular attention to the 3 chromosomes, 6 p, 17p, and 9p. First, while the chromosome region around $6 \mathrm{p}$ does not reveal a major presence of a TSG it does show a high level of expression of $\mathrm{LOH}$ in ACC and cutaneos melanoma. In contrast, the $17 \mathrm{p}$ and $9 \mathrm{p}$ regions included the TSG p53 and p16. In particular, p16/CDKN2 loci have been reported in previous studies that have a high level of incidence of $\mathrm{LOH}$ in cutaneos melanoma and ACC $(10,15)$.

We therefore analyzed in this study, the molecular biological characteristics of MMM and ACC and identified the p16/CDKN2 sequence.

\section{Materials and methods}

Tissue samples. Tissue samples were taken from 27 patients, 12 with MMMs and 15 with ACCs of the head and neck, who attended the Hospital of the Research Center for Charged Particle Therapy, NIRS, during the 2 years from 2002 through 2003 (Table I). Informed consent was obtained from all patients and also from their families. In addition, this study was approved by the institutional ethics committee in NIRS and also by the Tokyo Dental College. Normal tissue specimens as control were prepared from each patient's peripheral blood samples at the time of biopsy. None of the tumors and normal samples had undergone chemotherapy and radiotherapy prior to biopsy. All tissues resected for biopsy were prepared using a $10 \%$ formalin solution for pathologic diagnosis. Histopathologic diagnosis was performed according to the International Classification of Tumors (16).

All normal samples were prepared by immediate DNA extraction by the method described below.

Tumor DNA extraction from paraffin sections and normal DNA extraction from blood. Multiple $10-\mu \mathrm{m}$ sections were cut and mounted on silanated slides and left overnight at $37^{\circ} \mathrm{C}$. They were then dewaxed with xylene and water with different concentration levels of alcohol being successively added. The sections were lightly stained in Harris hematoxylin and compared with a hematoxylin and eosin-stained section on the same block. All samples had histologically confirmed MMM or ACC of the head and neck, and the tumor samples for DNA extraction were checked by observing in biopsy to ensure that they consisted of more than $80 \%$ tumor cells. Genomic DNA was extracted from several paraffin-embedded sections of all tumor samples using Takara DEXPAT ${ }^{\circledR}$ (Takara Bio Inc, Shiga, Japan). A standard protocol of DEXPAT ${ }^{\circledR}$ is shown below. Three $10-\mu \mathrm{m}$ thick paraffin-embedded tissue sections were prepared and placed in a microcentrifuge tube using sterilized tweezers. Of a gently stirred DEXPAT solution, $0.5 \mathrm{ml}$ per bottle was added to the centrifuging tube and mixed with the sample to remove the resin. The microcentrifuge
Table I. Summary of clinical features in 12 MMMs and 15 ACCs.

\begin{tabular}{|c|c|c|c|c|}
\hline Sample no. & Patient no. & Location & Age & Gender \\
\hline \multicolumn{5}{|l|}{ MMM } \\
\hline 1 & 9 & Palate & 69 & M \\
\hline 2 & 11 & Nasal & 77 & M \\
\hline 3 & 17 & Nasal & 77 & $\mathrm{~F}$ \\
\hline 4 & 29 & Nasal & 78 & M \\
\hline 5 & 48 & Maxillary sinus & 78 & M \\
\hline 6 & 49 & Nasal & 77 & $\mathrm{~F}$ \\
\hline 7 & 52 & Maxillary sinus & 53 & M \\
\hline 8 & 62 & Maxillary sinus & 52 & M \\
\hline 9 & 66 & Nasal & 66 & M \\
\hline 10 & 69 & Palate & 62 & M \\
\hline 11 & 83 & Ethmodial sinuses & 55 & $\mathrm{~F}$ \\
\hline 12 & 89 & Orbit & 55 & M \\
\hline \multicolumn{5}{|l|}{$\mathrm{ACC}$} \\
\hline 1 & 7 & Sublingual gland & 49 & M \\
\hline 2 & 13 & Parotid gland & 58 & $\mathrm{~F}$ \\
\hline 3 & 27 & Hard palate & 44 & M \\
\hline 4 & 30 & Epipharynx & 45 & $\mathrm{~F}$ \\
\hline 5 & 32 & Maxillary sinus & 49 & M \\
\hline 6 & 54 & Lacrimal gland & 76 & $\mathrm{~F}$ \\
\hline 7 & 59 & Maxillary sinus & 64 & M \\
\hline 8 & 64 & Tongue & 44 & M \\
\hline 9 & 73 & Epipharynx & 26 & $\mathrm{~F}$ \\
\hline 10 & 75 & Parotid gland & 56 & $\mathrm{~F}$ \\
\hline 11 & 81 & External acoustic meatus & 50 & $\mathrm{~F}$ \\
\hline 12 & 86 & Epipharynx & 45 & $\mathrm{~F}$ \\
\hline 13 & 91 & Parotid gland & 52 & $\mathrm{~F}$ \\
\hline 14 & 96 & Maxillary sinus & 40 & M \\
\hline 15 & 98 & Maxillary sinus & 37 & $\mathrm{~F}$ \\
\hline
\end{tabular}

MMM, malignant mucosal melanoma; ACC, adenoid cystic carcinoma; M, male; $\mathrm{F}$, female.

tube was heated to and kept at $100^{\circ} \mathrm{C}$ for $10 \mathrm{~min}$ in a block heater and then centrifuged at $12,000 \mathrm{rpm}$ for $10 \mathrm{~min}$ at $4^{\circ} \mathrm{C}$. The thin paraffin layer was removed from the tube wall and the supernatant was collected with a micropipette. After the DNA samples had been extracted by phenol-chloroform extraction and refined, they were washed and precipitated with ethanol. The concentrations of extracted DNA were estimated by a spectrophotometric method and the DNA samples were kept at $-80^{\circ} \mathrm{C}$.

Normal cells were prepared from peripheral blood samples as control. The blood samples were used for analysis with the Dr.GenTLE ${ }^{\circledR}$ (Takara Bio Inc) gene trapping kit. This kit is composed of three solutions; GenTLE ${ }^{\circledR}$ solution I, II, and III. GenTLE solution I lyses blood cells immediately after adding it to the whole blood, and a non-charged complex with nucleic acids is formed. The complex is collected by centrifugation, and the DNA precipitates are washed with GenTLE solution II. Then GenTLE solution III is added to isolate DNAs only, and DNAs are precipitated by adding isopropanol. The concentrations of the extracted DNA were estimated by a 
Table II. Microsatellite markers used in our LOH study in MMMs and ACCs.

\begin{tabular}{|c|c|c|}
\hline Location & Sequence & $\begin{array}{l}\text { Product } \\
\text { size (bp) }\end{array}$ \\
\hline \multicolumn{3}{|l|}{ MMM } \\
\hline D1S160 & $\begin{array}{l}\text { F 5'-GCATCTAGCAAACAGCATGTG-3' } \\
\text { R 5'-GCTGGAGGGCAGTGAAACT-3' }\end{array}$ & 156 \\
\hline D1S243 & $\begin{array}{l}\text { F 5'-CACACAGGCTCACATGCC-3' } \\
\text { R 5'-GCTCCAGCGTCATGGACT-3' }\end{array}$ & 209 \\
\hline D9S104 & $\begin{array}{l}\text { F 5'-GATCTGGGTATGTCTTTCTG-3' } \\
\text { R 5'-ACTGGGACTCTAACTAATGT-3' }\end{array}$ & 181 \\
\hline D6S310 & $\begin{array}{l}\text { F 5'-GATCCAGATTGCAGAAGG-3' } \\
\text { R 5'-GAAACAGGACCAGTAGGATAT G-3' }\end{array}$ & 159 \\
\hline D9S736 & $\begin{array}{l}\text { F 5'-TTCTAGACCTCTCAGCAGAC-3' } \\
\text { R 5'-GATAGTGTTGGAGACACCAG-3' }\end{array}$ & 157 \\
\hline D9S162 & $\begin{array}{l}\text { F 5'-GCAATGACCAGTTAAGGTTC-3' } \\
\text { R 5'-AATTCCCACAACAAATCTCC-3' }\end{array}$ & 181 \\
\hline D9S171 & $\begin{array}{l}\text { F 5'-AGCTAAGTGAACCTCATCTCTGTCT-3' } \\
\text { R 5'-ACCCTAGCACTGATGGTATAGTCT-3' }\end{array}$ & 159 \\
\hline D10S254 & $\begin{array}{l}\text { F 5'-ACTCCTTCCCATGTAGGTACC-3' } \\
\text { R 5'-TCCTGTTAAGATGTTACTGAG-3' }\end{array}$ & 98 \\
\hline D11S29 & $\begin{array}{l}\text { F 5'-TCTAGCTCCACCATCCTGTG-3' } \\
\text { R 5'-ACAACACACTGCCACAAGAC-3' }\end{array}$ & 143 \\
\hline TP53 & $\begin{array}{l}\text { F 5'-TTGCCTCTTTCCTAGCACTG-3' } \\
\text { R 5'-CCAAGACTTAGTACCTGAAG-3' }\end{array}$ & 103 \\
\hline \multicolumn{3}{|l|}{ ACC } \\
\hline D6S310 & $\begin{array}{l}\text { F 5'-GATCCAGATTGCAGAAGG-3' } \\
\text { R 5'-GAAACAGGACCAGTAGGATATG-3' }\end{array}$ & 159 \\
\hline D6S311 & $\begin{array}{l}\text { F 5'-ATGTCCTCATTGGTGTTGTG-3' } \\
\text { R 5'-GATTCAGAGCCCAGGAAGAT-3' }\end{array}$ & 62 \\
\hline D6S441 & $\begin{array}{l}\text { F 5'-AACAATATTTGGTGACTGTTAAAGG-3' } \\
\text { R 5'-TGGACAAATTGATTAGGAAGTAAAG-3' }\end{array}$ & 103 \\
\hline D9S171 & $\begin{array}{l}\text { F 5'-AGCTAAGTGAACCTCATCTCTGTCT-3' } \\
\text { R 5'-ACCCTAGCACTGATGGTATAGTCT-3' }\end{array}$ & 159 \\
\hline D12S391 & $\begin{array}{l}\text { F 5'-AACAGGATCAATGGATGCAT-3' } \\
\text { R 5'-TATTGGACAGTAAAGAAACCTGC-3' }\end{array}$ & 135 \\
\hline D12S1301 & $\begin{array}{l}\text { F 5'-ACACAGATGTGCATCTATCTCG-3' } \\
\text { R 5'-TATTGGACAGTAAAGAAACCTGC-3' }\end{array}$ & 132 \\
\hline D12S1064 & $\begin{array}{l}\text { F 5'-AATATTGACTTTCTCTTGCTACC-3' } \\
\text { R 5'-ACTACTCCAAGGTTCCAGCC-3' }\end{array}$ & 80 \\
\hline TP53 & $\begin{array}{l}\text { F 5'-TTGCCTCTTTCCTAGCACTG-3' } \\
\text { R 5'-CCAAGACTTAGTACCTGAAG-3' }\end{array}$ & 103 \\
\hline D19S210 & $\begin{array}{l}\text { F 5'-TCACACTCACTGGTCTCTC -3' } \\
\text { R 5'-GGTGTGCCTGTGTGTAAAAG-3' }\end{array}$ & 57 \\
\hline D19S246 & $\begin{array}{l}\text { F 5'-AGAGTGAGATTCCACCTTTC-3' } \\
\text { R 5'-GAAACACATCATTTACCCAC-3' }\end{array}$ & 64 \\
\hline
\end{tabular}

spectrophotometric method and the DNA samples were kept at $-80^{\circ} \mathrm{C}$. From each DNA sample, $50 \mathrm{ng} / \mu 1$ was used for the template of the PCR amplification procedure.

PCR and microsatellite analysis. We used 17 microsatellite markers from among those on 1p32, 6q23-25, 9p21, 10q23-25, 11q23.3, 12q12-13, 17p13.1, and 19q13.1 (Table II). All primers were obtained from Sigma-Aldrich Japan K.K. (Hokkaido, Japan). The DNA fragments of the above DNA
Table III. p16/CDKN2 oligonucleotide primers.

\begin{tabular}{llc}
\hline p16/CDKN2 & \multicolumn{1}{c}{ Sequence } & $\begin{array}{r}\text { Product } \\
\text { size (bp) }\end{array}$ \\
\hline Exon 1 & $\begin{array}{l}\text { 5'-GAAGAAAGAGGAGGGGTG-3' } \\
\text { Exon 2 }\end{array}$ & $\begin{array}{l}\text { 5'-GCGCTACCTGATTCCAATTC-3' } \\
\text { 5'-ACACAAGCTTCCTTTCCGTCAT-3' }\end{array}$ \\
& 5'-TCTGAGCTTTGGAAGCTCT-3' & 426 \\
Exon 3 & 5'-TTGATTATTTTGTTTTTTTGGTAGGTT-3' & 161 \\
& 5'-CAAATTCTCAAATCATCAATCCTCACCT-3' & \\
Exon 4 & 5'-AGGAATTCGGTAGGGACGGCAAGAGAGG-3' & 215 \\
& 5'-GAAGCTTGGGGGAAGGCATATATCTACG-3' & \\
\hline
\end{tabular}

sample were amplified with PCR in a $10-\mu 1$ final volume containing 0.25 units of HotStarTaq ${ }^{\circledR}$ DNA polymerase (Qiagen GmbH, Hilden, Germany) in 10X PCR buffer (50 mM KCL, $10 \mathrm{mM}$ Tris-Cl, $\mathrm{pH} 8.0,1.5 \mathrm{mM} \mathrm{MgCl}_{2}$ ), $0.2 \mathrm{mM}$ deoxynucleotide triphosphate, $0.2 \mu \mathrm{M}$ of each primer, $2.5 \mathrm{mM}$ of $\mathrm{MgCl}_{2}$ and $2.5 \mathrm{ng}$ genomic DNA. The amplification protocol specifies initial denaturation for $15 \mathrm{~min}$ at $94^{\circ} \mathrm{C}, 40$ cycles of $20 \mathrm{sec}$ each at $94^{\circ} \mathrm{C}, 30 \mathrm{sec}$ at $62^{\circ} \mathrm{C}, 30 \mathrm{sec}$ at $72^{\circ} \mathrm{C}$, followed by a final extension step of $72^{\circ} \mathrm{C}$ for 6 min according to the protocol of Nakamoto et al (17). After dilution with an adequate volume of formamide-dye mixture $(95 \%$ formamide, 20 mM EDTA, $0.05 \%$ bromophenol blue, and $0.05 \%$ xylene cyanol), the PCR products were heat-denatured $\left(98^{\circ} \mathrm{C}, 5 \mathrm{~min}\right)$, chilled on ice, and electrophoresed on $6 \%$ urea-formamidepolyacrylamide gel at $3 \mathrm{~W}$ for $2 \mathrm{~h}$, depending on the fragment size. Silver staining of the gels was performed using the DNA silver staining kit (GE Healthcare UK Ltd, Buckinghamshire, UK). To ensure reproducibility in each sample with $\mathrm{LOH}$, all tests were performed under the same conditions.

We carried out the previously described process twice to confirm the reproducibility of the results.

Assessment of LOH and microsatellite instability (MSI). $\mathrm{LOH}$ in the tumor DNA samples was assessed by scanning densitometry and analyzed with NIH Image software (version 1.62, http://rsb.info.nih.gov/nih-image/). The intensities of the signals from the tumor DNA were compared with those of normal DNA as a control. The criterion for the presence of $\mathrm{LOH}$ was a reduction in signal intensity of $>50 \%$. Commonly deleted regions were defined by considering the loci most frequently showing $\mathrm{LOH}$, together with multiple interstitial deletions. MSI in the DNA samples was assessed as positive in cases with additional bands in the tumor sample that were not observable in the normal samples and in cases showing a band shift in the tumor sample that contrasted with the pattern of the normal bands.

Detection of p16/CDKN2 gene alteration by PCR-SSCP and auto-DNA sequence analysis. To screen the sequence variations of the $p 16 / C D K N 2$ gene, PCR-SSCP analysis was performed as described previously $(18,19)$. Four sets of oligonucleotide primers as summarized in Table III were used to amplify the entire coding region (exons 1 to 4 ) of the $p 16 / C D K N 2$ gene. Sequences for all annotated exons and adjacent intronic 
Table IV. Frequency of LOH at each microsatellite marker in MMMs and ACCs.

\begin{tabular}{|c|c|c|c|c|c|}
\hline \multicolumn{3}{|c|}{ MMM } & \multicolumn{3}{|c|}{ ACC } \\
\hline Locus symbol & $\mathrm{LOH} /$ informative cases & Frequency of LOH (\%) & Locus symbol & LOH/informative cases & Frequency of $\mathrm{LOH}(\%)$ \\
\hline D6S310 & $1 / 12$ & 8.3 & D6S310 & $1 / 15$ & 6.7 \\
\hline D9S171 & $4 / 12$ & 33.3 & D9S171 & $8 / 15$ & 53.3 \\
\hline TP53 & $0 / 10$ & 0.0 & TP53 & $0 / 8$ & 0.0 \\
\hline D1S160 & $0 / 8$ & 0.0 & D6S441 & $0 / 15$ & 0.0 \\
\hline D1S243 & $0 / 12$ & 0.0 & D6S311 & $0 / 13$ & 0.0 \\
\hline D9S104 & $0 / 11$ & 0.0 & D12S391 & $6 / 15$ & 40.0 \\
\hline D9S736 & $1 / 12$ & 8.3 & D12S1301 & $1 / 15$ & 6.7 \\
\hline D9S162 & $1 / 12$ & 8.3 & D12S1064 & $0 / 14$ & 0.0 \\
\hline D10S254 & $1 / 12$ & 8.3 & D19S210 & $1 / 15$ & 6.7 \\
\hline D11S29 & $1 / 10$ & 10.0 & D19S246 & $1 / 14$ & 7.1 \\
\hline
\end{tabular}

The former 3 markers are common to MMM and ACC; the remaining 7 markers are specific to each.

\begin{tabular}{lllllllllllll}
\hline MMM & 1 & 2 & 3 & 4 & 5 & 6 & 7 & 8 & 9 & 10 & 11 & 12 \\
\hline D1S160 & 0 & 0 & 0 & 0 & $\times$ & $\times$ & $\times$ & 0 & 0 & 0 & 0 & $\times$ \\
D1S243 & 0 & 0 & 0 & 0 & 0 & 0 & 0 & 0 & 0 & 0 & 0 & 0 \\
D6S310 & 0 & 0 & 0 & 0 & 0 & 0 & 0 & 0 & 0 & 0 & 0 & 0 \\
D9S104 & 0 & 0 & 0 & 0 & 0 & $\times$ & 0 & 0 & 0 & 0 & 0 & 0 \\
D9S162 & 0 & 0 & 0 & 0 & 0 & 0 & 0 & 0 & 0 & 0 & 0 & 0 \\
D9S171 & 0 & 0 & 0 & 0 & 0 & 0 & 0 & 0 & 0 & 0 & 0 & 0 \\
D9S736 & 0 & 0 & 0 & 0 & 0 & 0 & 0 & 0 & 0 & 0 & 0 & 0 \\
D10S254 & 0 & 0 & 0 & 0 & $\times$ & 0 & 0 & 0 & 0 & 0 & 0 & 0 \\
D11S29 & 0 & 0 & 0 & 0 & 0 & 0 & 0 & $\times$ & 0 & 0 & 0 & 0 \\
TP53 & 0 & 0 & 0 & 0 & 0 & $\times$ & 0 & 0 & 0 & 0 & 0 & $\times$
\end{tabular}

\begin{tabular}{llllllllllllllll}
\hline ACC & 1 & 2 & 3 & 4 & 5 & 6 & 7 & 8 & 9 & 10 & 11 & 12 & 13 & 14 & 15 \\
\hline D6S310 & 0 & 0 & 0 & 0 & 0 & 0 & 0 & 0 & 0 & 0 & 0 & 0 & 0 & 0 & 0 \\
D6S311 & 0 & 0 & 0 & 0 & $\times$ & $\times$ & 0 & 0 & 0 & 0 & 0 & 0 & 0 & 0 & 0 \\
D6S441 & 0 & 0 & 0 & 0 & 0 & 0 & 0 & 0 & 0 & 0 & 0 & 0 & 0 & 0 & 0 \\
D9S171 & 0 & 0 & 0 & 0 & 0 & 0 & 0 & 0 & 0 & 0 & 0 & 0 & 0 & 0 & 0 \\
D12S391 & 0 & 0 & 0 & 0 & 0 & 0 & 0 & 0 & 0 & $\bullet$ & 0 & 0 & 0 & 0 & 0 \\
D12S1064 & 0 & 0 & 0 & 0 & 0 & 0 & 0 & 0 & 0 & 0 & 0 & $\times$ & 0 & 0 & 0 \\
D12S1301 & 0 & 0 & 0 & 0 & 0 & 0 & 0 & 0 & 0 & 0 & 0 & 0 & 0 & 0 & 0 \\
TP53 & $\times$ & $\times$ & $\times$ & $\times$ & $\times$ & $\times$ & $\times$ & 0 & 0 & 0 & 0 & 0 & 0 & 0 & 0 \\
D19S210 & 0 & 0 & 0 & 0 & 0 & 0 & 0 & 0 & 0 & 0 & 0 & 0 & 0 & 0 & 0 \\
D19S246 & 0 & 0 & 0 & 0 & 0 & 0 & 0 & 0 & 0 & $\times$ & 0 & 0 & 0 & 0 & 0
\end{tabular}

$\begin{array}{ll}\text { : }: \mathrm{LOH}=\text { Loss of Heterozygosity } & \text { @: MSI }=\text { Microsatellite instability } \\ \mathrm{O}: \mathrm{ROH}=\text { Retention of Heterozygosity } & \mathrm{x} \cdot \mathrm{NI}=\text { not informative }\end{array}$

Figure 1. Deletion mapping of chromosomes 1p, 6q, 9p, 10q, 11q, and 17p in 12 MMMs, and chromosomes $6 \mathrm{q}, 9 \mathrm{p}, 12 \mathrm{q}, 17 \mathrm{p}$, and $19 \mathrm{q}$ in 15 ACCs. Case numbers are shown at the top and locus symbols on the left.

sequences were extracted using the sequences made public on the NCBI database (http://www.ncbi.nlm.nih.gov/). Primers for PCR amplification and sequencing were designed using the Primer 3 program (version 0.2, http://frodo.wi.mit.edu/ cgi-bin/primer3/primer3_www.cgi). PCR was carried out in a final volume of $25 \mu \mathrm{l}$ of a reaction mixture containing $1 \mathrm{X}$ LA-PCR buffer (Takara Bio Inc), $2 \mu \mathrm{M}$ of each primer, $200 \mu \mathrm{M}$ of each dNTP, $100 \mathrm{ng}$ of template DNA, and 0.01 unit of LA-Taq DNA polymerase (Takara Bio Inc). Thirtyfive cycles of denaturation were performed at $94^{\circ} \mathrm{C}$ for $10 \mathrm{sec}$ each, followed by annealing at $54^{\circ} \mathrm{C}$ for $10 \mathrm{sec}$, and extension at $72^{\circ} \mathrm{C}$ for $30 \mathrm{sec}$. After amplification, the PCR products were electrophoresed on $10 \%$ polyacrylamide gels under different conditions at $4^{\circ} \mathrm{C}, 15^{\circ} \mathrm{C}$, and room temperature.
After electrophoresis, the gel was silver-stained using a DNA silver staining kit (GE Healthcare UK Ltd). Suspected mutations were identified by re-amplification with the same primer used in PCR-SSCP analysis, ligated into pCR2.1 vector (Invitrogen Japan K.K., Tokyo, Japan), and sequenced on an Applied Biosystems 3730xl DNA analyzer (Applied Biosystems Ltd, CA, USA).

\section{Results}

Analysis of LOH and MSI in MMM. We analyzed tumors from 12 patients with MMM using PCR-LOH assay with 10 microsatellite markers. $\mathrm{LOH}$ was detected in six of 12 samples $(50.0 \%)$ in at least one region. The incidence of $\mathrm{LOH}$ for 10 microsatellite markers is shown in Table IV. The results of the $\mathrm{LOH}$ analysis in tumor samples are shown in the deletion map in Fig. 1. The highest incidence of $\mathrm{LOH}$ was found at the marker D9S171 at 9p21 (33.3\%). This locus has already been reported as a candidate TSG locus for cutaneous melanoma (20). The marker D9S171 has been mapped around the p16/ CDKN2 gene locus on 9p21 (21).

Another frequently occurring LOH location was the marker D6S310 at 6q23-25 (8.3\%), D9S736 at 9p21 (8.3\%), D9S162 at $9 \mathrm{p} 21(8.3 \%)$, and D11S29 at 11q23.3 (10.0\%). In addition, incidence of MSI was found at the microsatellite marker D9S104 in sample no.8. For all of them, it was not possible to assume a common deletion domain because expression was $\leq 20 \%$.

Typical examples of LOH, informative (INF) and not informative (NI) cases are shown in Fig. 2.

Analysis of LOH and MSI in ACC. The results of PCR-LOH analysis of the tumor samples with LOH are shown in Fig. 1, and Table IV. Fifteen tumor samples and normal tissues were studied for LOH using 10 microsatellite markers. We detected $\mathrm{LOH}$ in $80.0 \%(12 / 15)$ of the ACCs, the most frequently deleted locus being D9S171 at 9p21. Of the 15 informative cases, $8(53.3 \%)$ showed LOH at D9S171. In the location of D12S391, a frequency of $\mathrm{LOH}$ of $40 \%(6 / 15)$ was detected. In addition, frequently detected loci were D6S310 at 6q23-25 


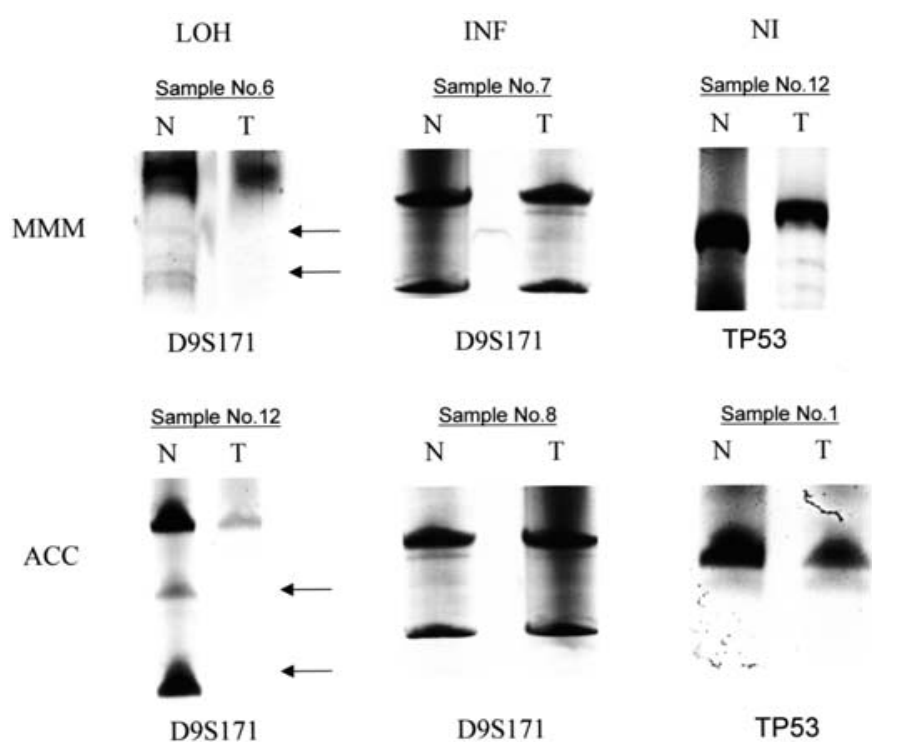

Figure 2. Illustration of microsatellite polymorphism analysis in MMM and ACC specimens. Case numbers are shown at the top, and locus symbols on the left. Paired normal $(\mathrm{N})$ and tumor $(\mathrm{T})$ samples for patients $1,6,7,8$, and 12 demonstrating loss of the upper allele $(\mathrm{LOH})$, retained heterozygosity (INF) and not informative (NI), respectively.

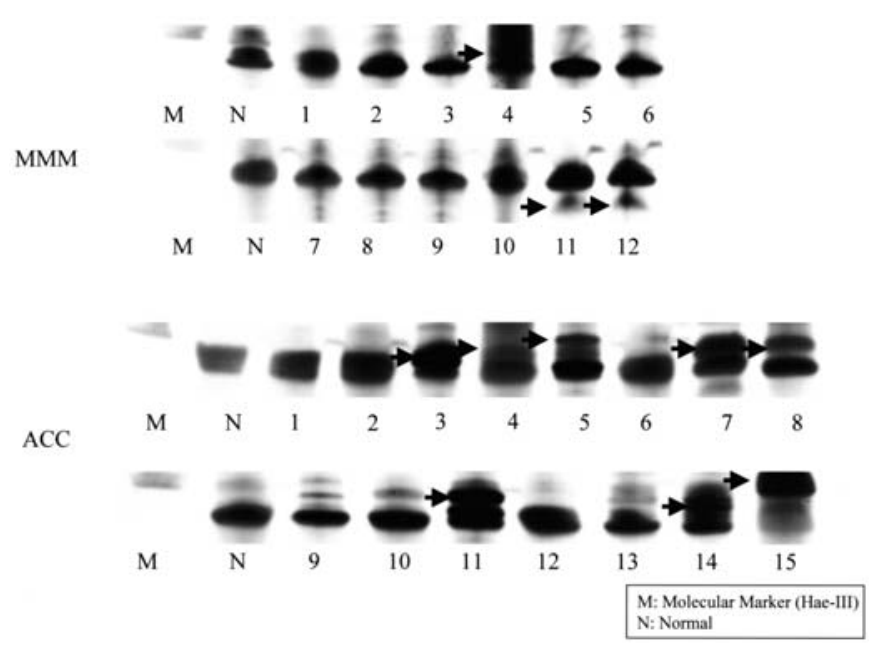

Figure 3. PCR-SSCP analysis for exon 4 of the $p 16 / C D K N 2 A$ gene in MMMs and ACCs. Case numbers are shown below each column. N, corresponding normal tissue; $\mathrm{T}$, tumor tissue.

(6.7\%), D12S1301 at 12q12-13 (6.7\%), D19S210 at 19q13.1 $(6.7 \%)$, and D19S246 at 19q13.1 (7.1\%). MSI was not found in ACCs. Interestingly, a locus of D9S171 overlapped with the proximal, commonly deleted region in MMM.

Typical examples of LOH, informative (INF) and not informative (NI) cases are shown in Fig. 2.

SSCP and auto-sequencing of the p16/CDKN2 gene in MMM. We investigated exons 1 to 4 of the $p 16 / C D K N 2$ gene by PCR-SSCP analysis in 12 primary tumors. We found mobility shifts in 3 cases, sample nos. 4,11 , and 12, of the 8 cases with LOH detected at D9S171 (30.0\%) in exon 4 (Fig. 3), and these bands were analyzed by automatic sequencer. In tissue sample no. 4, 3 different nucleotide substitutions were

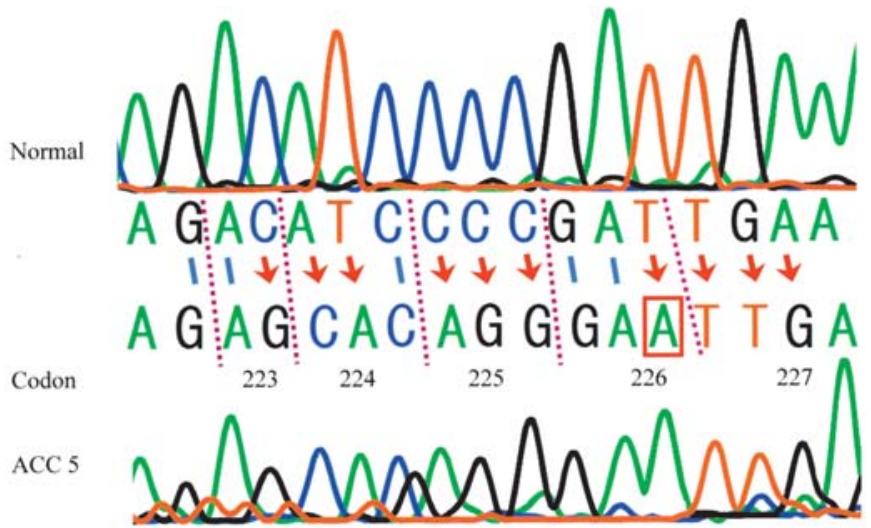

Figure 4. Sequencing analysis of the $16 / C D K N 2$ gene. The 223rd codon was changed from AC (Asp) to AG (Glu), the 224th codon was changed from ATC (Ile) to CAC (His), the 225th codon was changed from CCC (Pro) to AGG (Arg), and the 226th codon was changed from GAT (Asp) to GAAT (1 bp insertion, Glu) in ACC sample no. 5.

Table V. Somatic mutations of the p16/CDKN2 gene in MMMs and ACCs.

\begin{tabular}{llll}
\hline Case & Base substitution & Codon & Amino-acid substitution \\
\hline Sample no. 4 & CCC $\rightarrow$ TCC & 225 & Pro $\rightarrow$ Ser \\
in MMMs & GAT $\rightarrow$ ATG & 226 & Asp $\rightarrow$ Met \\
& TGA $\rightarrow$ GTGA & 227 & Stop $\rightarrow$ Val (1-bp insertion) \\
Sample no. 5 & GAC $\rightarrow$ GAG & 223 & Asp $\rightarrow$ Glu \\
in ACCs & ATC $\rightarrow$ CAC & 224 & Ile $\rightarrow$ His \\
& CCC $\rightarrow$ AGG & 225 & Pro $\rightarrow$ Arg \\
& GAT $\rightarrow$ GAAT & 226 & Asp $\rightarrow$ Glu (1-bp insertion) \\
Sample no. 14 & CCC $\rightarrow$ deletion & 225 & 3-bp deletion \\
in ACCs & & & \\
\hline
\end{tabular}

identified. These substitutions were from CCC to TCC at codon 225, GAT to ATG at codon 226, and TGA to GTGA (1-bp insertion) at codon 227, resulting in an amino acid substitution, Pro to Ser, Asp to Met, and Stop to Val (Table V). However, nucleotide substitutions were not detected in samples no. 11 and 12 .

SSCP and auto-sequencing of the p16/CDKN2 gene in ACC. By PCR-SSCP analysis of exons 1 to 4 of the p16/CDKN2 gene, we identified mobility shifts in 8 of 15 cases $(53.3 \%)$ in exon 4 (Fig. 3). Auto-sequencer analysis was performed, on sample no. 5, and 4 novel nucleotide substitutions at exon 4 were identified. These substitutions were from GAC to GAG at codon 223, ATC to CAC at codon 224, CCC to AGG at codon 225, and GAT to GAAT (1-bp insertion) at codon 226, and resulted in an amino acid replacement from Asp to Glu, Ile to His, Pro to Arg, and Asp to Glu (Fig. 4, Table V). Sample no. 14 showed a frameshift mutation at codon 225 (CCC, 3-bp deletion) (Table V). While it was possible to detect a band shift for sample nos. 3, 4, 7, 8, 11, and 15 (in $\mathrm{SSCP}$ ), investigation of the gene sequence using a sequencer showed that no sequence abnormality or shift had occurred. 


\section{Discussion}

MMM of the head and neck constitute approximately half of all malignant melanoma cases (22). These melanomas occur mainly in the upper respiratory tract in $56 \%$ and oral cavity in $44 \%$ (23). Within the oral cavity, the commonest site is the hard palate in up to $80 \%$, followed, in decreasing order of frequency, by the upper and lower gingiva and mucosa of buccal. According to the report of Shah et al, MMM of the head and neck exhibit a far more aggressive behavior than on the skin (24). They are more prone to metastasis into and recurrence in regional and distant sites.

ACC generally developed in the major and minor salivary glands. Seifert et al reported in the WHO International histological classification of tumors that ACC is considered to have aggressive biological characteristics in terms of local recurrence, perineural spread and late distant metastasis (25). Among all salivary gland tumors, approximately $40 \%$ are malignant ones, and when the ACC are combined with mucoepidermoid carcinoma the total amounts to $80 \%$ or more. ACCs occur mainly in the palatine gland in approximately $35 \%$ and in the sublingual gland in approximately $30 \%$ (26). ACC has characteristics of a tendency towards permeation and intensive recurrence, and prognosis is generally poor.

In this study, we have analyzed and examined the molecular biological characteristics of MMM and ACC, by analyzing $\mathrm{LOH}$ and MSI for allelic imbalance. We carried out investigations to achieve a better understanding of the extent of alterations affecting chromosomes 1p32, 6q23-25, 9p21, 10q23-25, 11q23.3, 12q12-13, 17p13.1, and 19q13.1. From the results, $\mathrm{LOH}$ at one or more loci was found in 6 of the 12 informative MMM at $50 \%$ and 8 of the 15 informative ACC at $80 \%$. The most frequently deleted region was D9S171 in the location of the $p 16 / C D K N 2$ gene on $9 \mathrm{p} 21$. The frequency rate was $33.3 \%$ in MMM and 53.3\% in ACC. On the other hand, a $40 \%$ level of $\mathrm{LOH}$ incidence was detected in the D12S391 region located in chromosome 12q12-13. Yet, we focused our attention on microsatellite deletion in this region in MMM and ACC because the literature does not evidence any significant presence of TSG in this region. Therefore the hitherto unreported presence of some as-yet unknown TSGs cannot be ruled out. Further study is needed to shed light on this. $\mathrm{LOH}$ at a low frequency was detected on D6S310, D9S162, D9S736, D11S29, D12S1301, D19S210, and D19S246. However the incidence of LOH in all of these locations fell short of $20 \%$ and it was therefore not justified to consider them as common deletion domains. In this context, we are particularly interested in two regions, excluding p16/ CDKN2 which is a microsatellite domain of D9S171. The two regions are $6 \mathrm{q} 23 / 25$, which is a domain of D6S310, and p53 which is located at $17 \mathrm{p} 13.1$. The reason why these two regions arouse our particular interest lies in the fact that they do not exhibit LOH expression. Our research thrust will therefore concentrate on an analysis of the particular molecular biological characteristics of the $9 \mathrm{p} 21$ and $p 16 / C D K N 2$ regions.

The domain of the $p 16 / C D K N 2$ gene is one of the $p 16$ family, and the $p 16$ gene has a length of $25 \mathrm{~kb}$ and is situated on chromosome 9p21. It has been reported in the earlier literature to be involved in various cancers (27). One role played by p16 as a TSG is that the growth suppressing activity of the retinoblastoma susceptibility gene product, $p R b$, is down-regulated by cyclin-dependent kinases 4 and 6 (CDK4 and CDK6) whose activity is negatively regulated by CDK inhibitors of the p16 family $(28,29)$. The $p 16$ gene may be a critical target in human carcinomas. Caldas et al reported that frequent allelic losses were detected in location of the p16/CDKN2 gene in many types of tumors including breast cancer, bladder cancer, head and neck cancer, esophageal SCCs, pancreatic adenocarcinomas and non-small cell lung carcinomas (30). In particular, Nakanishi et al reported that the p16/CDKN2 gene is commonly deleted in head and neck SCCs (53\%) (5). These results suggest that a putative suppressor associated with many cancers is located at this region, but there have been no reports of $p 16 / C D K N 2$ gene $\mathrm{LOH}$ in both MMM and ACC of the head and neck. Our attention therefore focuses on mutation in $p 16 / C D K N 2$ as a TSG.

In this study, we have examined somatic mutations of the p16/CDKN2 gene to determine whether these are associated with MMM and ACC of the head and neck. Eight somatic mutations of the $p 16 / C D K N 2$ gene were detected in 3 patients ( 1 MMM and 2 ACCs). These mutations have not been identified in any other type of tumor (Table V).

Previous studies have reported somatic mutation in exon 2 of $p 16 / C D K N 2(10,31)$. Mutations have also been reported at codon 80 in salivary duct carcinomas (10). This finding aroused our interest. All mutations detected were located within exon 4 of the $p 16 / C D K N 2$ gene. Interestingly, we found 2 somatic mutations in the p16/CDKN2 gene in all samples of both MMM and ACC showing abnormal SSCP patterns, both mutations were present at codon 225 and codon 226, which created a truncated $p 16 / C D K N 2$ gene product. Thus, codon 225 and codon 226 may be mutational hot spots of the p16/CDKN2 gene in MMM and ACC of the head and neck. These findings suggest that the $p 16 / C D K N 2$ gene has another potential tumor-suppression function, seeing that the mutation was detected in another domain not previously reported. However, the functional inactivation of $p 16 / C D K N 2$ by this mutation still remains to be clarified. For example, in ACC sample no. 5, a 1-bp insertion was detected in codon 226 , resulting in a sequence shift after stop codon 227 , disrupting the stop sequence. In order to determine the implications of this, the sequence following $p 16 / C D K N 2$ will need to be further clarified and the functionality of the proteins expressed confirmed in order to determine the influence of mutation at exon 4. On the other hand, a number of studies have found a relation between $p 16 / C D K N 2$ and the hypermethylation status of its promoter gene in ACC (32). Therefore, in further study, we need to identify the protein functionality of $p 16 / C D K N 2$. Apart from the three patients mentioned above, none of the patients showed evidence of mutation, but did reveal mobility shifts. We concluded that this might be a case of polymorphism. It is also possible that these mobility shifts resulted from an artifact occurring during the PCR-SSCP. We used 12-cm long $10 \%$ polyacrylamide gel strips during the process, and such short strips of gel can not be divided into bands with PCR-SSCP. This may be a weakness of the study design, and clarification of this point will require further study using longer gels.

We will cautiously approach the issue of whether there is a relation between the effectiveness of HIMAC radiotherapy 
and the biological characteristics of the $p 16 / C D K N 2$ gene. As mentioned above, on the one hand, p16/CDKN2 has an influence on the down-regulation of the cell cycle and, on the other, HIMAC is characterized by the unique feature that its radiation is effective on cells regardless of cell status and of the cell cycle. No analytical procedure for assessing the molecular biological effects of HIMAC radiation has been established yet. However, the discovery of $p 16 / C D K N 2$ mutations different from those of earlier literature publications might suggest the possibility of some relation between the effect of the HIMAC and these mutations.

Further studies are needed to clarify the role of the $p 16 /$ $C D K N 2$ gene in the development and progression of MMMs and ACCs of the head and neck.

\section{Acknowledgments}

We wish to express sincere gratitude to Dr Hirohiko Tsujii, Hospital of the Research Center for Charged Particle Therapy, National Institute of Radiological Sciences, for continuous guidance and encouragement. We would like to thank Associate Professor Jeremy Williams, Tokyo Dental College, for proof-reading this manuscript.

\section{References}

1. Tsujii H, Morita S, Miyamoto T, Mizoe J, Kamada T, Kato H, Tsuji H, Yamada S, Yamamoto N and Murata K: Experiences of carbon ion radiotherapy at NIRS. In: Proceedings of 7th International Meeting on Progress in Radio-Oncology ICRO/ OGRO 7. Kogelnik HD and Sedlmayer F (eds). Monduzzi Editore, Austria, pp393-405, 2002.

2. Kamada T, Tsujii H, Tsuji H, Yanagi T, Mizoe J, Miyamoto T, Kato H, Yamada S, Morita S, Yoshikawa K, Kandatsu S and Tateishi A: Efficacy and safety of carbon ion radiotherapy in bone and soft tissue sarcoma. J Clin Oncol 20: 4466-4471, 2002.

3. Miyamoto T, Yamamoto N, Nishimura H, Koto M, Tsujii H, Mizoe J, Kamada T, Kato H, Yamada S, Morita S, Yoshikawa K, Kandatsu S and Fujisawa T: Carbon ion radiotherapy for stage I non-small cell lung cancer. Radiother Oncol 66: 127-140, 2003.

4. Yamamoto N, Mizoe J, Numasawa H, Yokoe H, Uzawa K, Shibahara $\mathrm{T}$, Tsujii $\mathrm{H}$, Noma $\mathrm{H}$ and Tanzawa $\mathrm{H}$ : Allelic loss of chromosome 2 in human oral squamous cell carcinoma: correlation with lymph node metastasis. Oral Oncol 39: 64-68, 2003.

5. Nakanishi H, Wang XL, Imai FL, Kato J, Shiiba M, Miya T, Imai $\mathrm{Y}$ and Tanzawa $\mathrm{H}$ : Localization of a novel tumor suppressor gene loci on chromosome 9p21-22 in oral cancer. Anticancer Res 19: 29-34, 1999.

6. Yamashita Y, Miyakawa A, Mochida Y, Aisaki K, Yama M, Shiiba M, Watanabe T, Yokoe H, Uzawa K, Imai Y and Tanzawa H: Genetic aberration on chromosome 10 in human oral squamous cell carcinoma. Int J Oncol 20: 595-598, 2002.

7. Yamamoto N, Noma H and Shibahara T: Allelic imbalance on the long arm of chromosome 21 in human oral squamous cell carcinoma: relationship between allelic imbalances (LOH and MSI) and clinicopathologic features. Bull Tokyo Dental College 42: 211-223, 2001

8. Tomlinson IP, Beck NE and Bodmer WF: Allele loss on chromosome $11 \mathrm{q}$ and microsatellite instability in malignant melanoma. Eur J Cancer 32A: 1797-1802, 1996.

9. Stallmach I, Zenklusen P, Komminoth P, Schmid S, Perren A, Roos M, Jianming Z, Heitz PU and Pfaltz M: Loss of heterozygosity at chromosome 6q23-25 correlates with clinical and histologic parameters in salivary gland adenoid cystic carcinoma. Virchows Arch 440: 77-84, 2002.

10. Cerilli LA, Swartzbaugh JR, Saadut R, Marshall CE, Rumpel CA, Moskaluk CA and Frierson HF Jr: Analysis of chromosome $9 \mathrm{p} 21$ deletion and p16 gene mutation in salivary gland carcinomas. Hum Pathol 30: 1242-1246, 1999.
11. Walker GJ, Palmer JM, Walters MK and Hayward NK: A genetic model of melanoma tumorigenesis based on allelic losses. Genes Chromosomes Cancer 12: 134-141, 1995.

12. Deichmann M, Mollenhauer J, Helmke B, Thome M, Hartschuh W, Poustka A and Naher H: Analysis of losses of heterozygosity of the candidate tumour suppressor gene DMBT1 in melanoma resection specimens. Oncology 63: 166-172, 2002.

13. El-Rifai W, Rutherford S, Knuutila S, Frierson HF Jr and Moskaluk CA: Novel DNA copy number losses in chromosome 12q12-q13 in adenoid cystic carcinoma. Neoplasia 3: 173-178, 2001.

14. Yamamoto Y, Wistuba II, Kishimoto Y, Virmani AK, Vuitch F, Albores-Saavedra J and Gazdar AF: DNA analysis at p53 locus in adenoid cystic carcinoma: comparison of molecular study and p53 immunostaining. Pathol Int 48: 273-280, 1998.

15. Puizina-Ivic N, Pokupcic N, Musani V, Komar A, Kubat M, Furac I, Karija-Vlahovic M and Krizanac S: Alterations in CDKN2A locus as potential indicator of melanoma predisposition in relatives of non-familial melanoma cases. Croat Med J 44: 418-424, 2003

16. Wasi PN, Cohen B, Luthra UK and Torloni H: International histological classification of tumours, histological typing of oral and oropharyngeal tumours, 4 . WHO, Geneva, 1971.

17. Nakamoto D, Yamamoto N, Takagi R, Katakura A, Mizoe J and Shibahara T: Detection of tumor DNA in plasma using whole genome amplification. Bull Tokyo Dent Coll 47: 125-131, 2006.

18. Uzawa K, Suzuki H, Yokoe H, Tanzawa $\mathrm{H}$ and Sato K: Mutational state of $p 16 / C D K N 2$ and $V H L$ genes in squamouscell carcinoma of the oral cavity. Int J Oncol 7: 895-899, 1995.

19. Onda T, Uzawa K, Endo Y, Bukawa H, Yokoe H, Shibahara T and Tanzawa $\mathrm{H}$ : Ubiquitous mitochondrial creatine kinase downregulated in oral squamous cell carcinoma. Br J Cancer 94: 698-709, 2006.

20. Bogdan I, Xin H, Burg G and Boni R: Heterogeneity of allelic deletions within melanoma metastases. Melanoma Res 11 : 349-354, 2002.

21. Yakushiji T, Noma H, Shibahara T, Arai K, Yamamoto N, Tanaka C, Uzawa $\mathrm{K}$ and Tanzawa $\mathrm{H}$ : Analysis of a role for p16/CDKN2 expression and methylation patterns in human oral squamous cell carcinoma. Bull Tokyo Dent Coll 42: 159-168, 2001.

22. Chang AE, Karnell LH and Menck HR: The National Cancer Data Base Report on cutaneous and noncutaneous melanoma. Cancer 83: 1664-1678, 1998

23. Batsakis JD, Regezi JA, Solomon AR and Rice DH: The pathology of head and neck tumors - part 13: mucosal melanomas. Head Neck Surg 4: 404-412, 1982.

24. Shah JP, Huvos AG and Strog EW: Mucosal melanomas of the head and neck. Am J Surg 134: 531-535, 1977.

25. Seifert G and Sobin LH: Histological typing of salivary gland tumours. WHO International histological classification of tumours. 2nd edition. Springer-Verlag, Berlin, 1991.

26. Kawano S, Oobu K, Matsunaga K, Kawano E, Mitate E, Suzuki H, Kobayashi I, Kiyoshoma T and Nakamura S: A clinicostatistical study of 151 patients with salivary gland tumors. Jpn J Oral Maxillofac Surg 7: 393-400, 2006.

27. Cairns P, Mao L, Merlo A, Lee DJ, Schwab D, Eby Y, Tokino K, van der Riet P, Blaugrund JE and Sidransky D: Rates of p16(MTS1) mutations in primary tumors with 9p loss. Science 265: 415-416, 1994

28. Kamb A, Gruis NA, Weaver-Feldhaus J, Liu Q, Tavtigian SV, Stockert E, Day RS III, Johnson BE and Skolnick MH: A cell cycle regulator potentially involved in genesis of many tumor types. Science 246: 436-440, 1994.

29. Nobori T, Miura K, Wu DJ, Lois A, Takabayashi K and Carson DA: Deletions of the cyclin-dependent kinase-4 inhibitor gene in multiple human cancers. Nature 368: 753-756, 1994

30. Caldas C, Hahn SA, da Costa LT, Redston MS, Schutte M, Seymour AB, Weinstein CL, Hruban RH, Yeo CJ and Kern SE: Frequent somatic mutations and homozygous deletions of the p16 (MTS1) gene in pancreatic adenocarcinoma. Nat Genet 8: 27-32, 1994.

31. Lamperska K, Karezewska A, Kwiatkowska E and Mackiewicz A Analysis of mutations in the p16/CDKN2A gene in sporadic and familial melanoma in the Polish population. Acta Biochim Pol 49: 369-376, 2002.

32. Maruya S, Kurotaki H, Shimoyama N, Kaimori M, Shinkawa H and Yagihashi S: Expression of p16 protein and hypermethylation status of its promoter gene in adenoid cystic carcinoma of the head and neck. J Otorhinolaryngol 65: 26-32, 2003. 